\title{
Geological factors and mechanism of sinkhole development in Cho Don zinc-lead mining area, Bac Kan province, North of Vietnam
}

\author{
Nguyen Van Hoang ${ }^{1}$, Tran Quoc Cuong ${ }^{1}$, and S. A. Kasatkin ${ }^{2}$
}

Received 18 June 2020; accepted 2 July 2020; published 2 March 2022.

The Cho Don district of Bac Kan province in North Vietnam is rich in minerals. The most common among them are iron, lead and zinc ores found in large reserves. The Na Tum mine in Cho Don district, Bac Kan province, became functional in April 2007. However, since December 2007, a number of large sinkhole formations have been reported. Dewatering of the $\mathrm{Na}$ Tum mine is considered to be the main factor behind sinkhole formation. However, there are certain other causative factors and conditions of sinkhole development and formation, which have been identified in this paper. A quantitative soil mechanic model has been applied for determining the sinkhole sizes along with the soil physical and strength parameters of the soil. Moreover, the process of sinkhole development is studied in detail in terms of suffusion and suffosion, the removal of soil particles from the massif with or without a change in volume, respectively. Different geometric criteria have been used and applied for the identification of the soil suffusion/suffosion vulnerability and have proven the reliability of the analysis applicability. The site-specific hydrological and hydrogeological conditions such as groundwater (GW) level regime which create suffusion/suffosion conditions for the formation of soil-caves above karstic formation have been identified. The soil resistance analysis using horizontal stress based on the soil arching theory has been carried out to determine the sliding potential of a particular soil cylinder above the underground soil cave. The results are essential for preventing sinkhole development in the study area, and the application of the methodology would be very useful for other sinkhole-vulnerability analyses under similar conditions. KEYWORDS: Sinkhole; karstic; dewatering; suffusion/suffosion; soil arching; safety factor of sliding.

Citation: Hoang, Nguyen Van, Tran Quoc Cuong, and S. A. Kasatkin (2022), Geological factors and mechanism of sinkhole development in Cho Don zinc-lead mining area, Bac Kan province, North of Vietnam, Russ. J. Earth. Sci., 22, ES1004, doi:10.2205/2022ES000728.

\section{Introduction}

Vietnam has abundant diverse mineral resources, with nearly 5000 mines and ore spots of about 60

\footnotetext{
${ }^{1}$ Institute of Geological Sciences (IGS), VAST, Hanoi, Vietnam

${ }^{2}$ Far Eastern Geological Institute (FEGI), FEB RAS, Vladivostok, Russia

Copyright 2022 by the Geophysical Center RAS. http://rjes.wdcb.ru/doi/2022ES000728-res.html
}

different minerals. Mining and processing of mineral resources have been important for the national economy, as it has contributed about $9.6-10.6 \%$ of the national GDP since 2000 [Tran Trung Kien and Pham Quang Tu, 2011. However, the exploitation of these mineral resources has been leading to different geological hazards that cause serious harm to humans and property loss.

The Cho Don district in Bac Kan province is one such area with concentrated mineral resources. The most common minerals found are iron, lead and zinc. The mines that have been explored - 


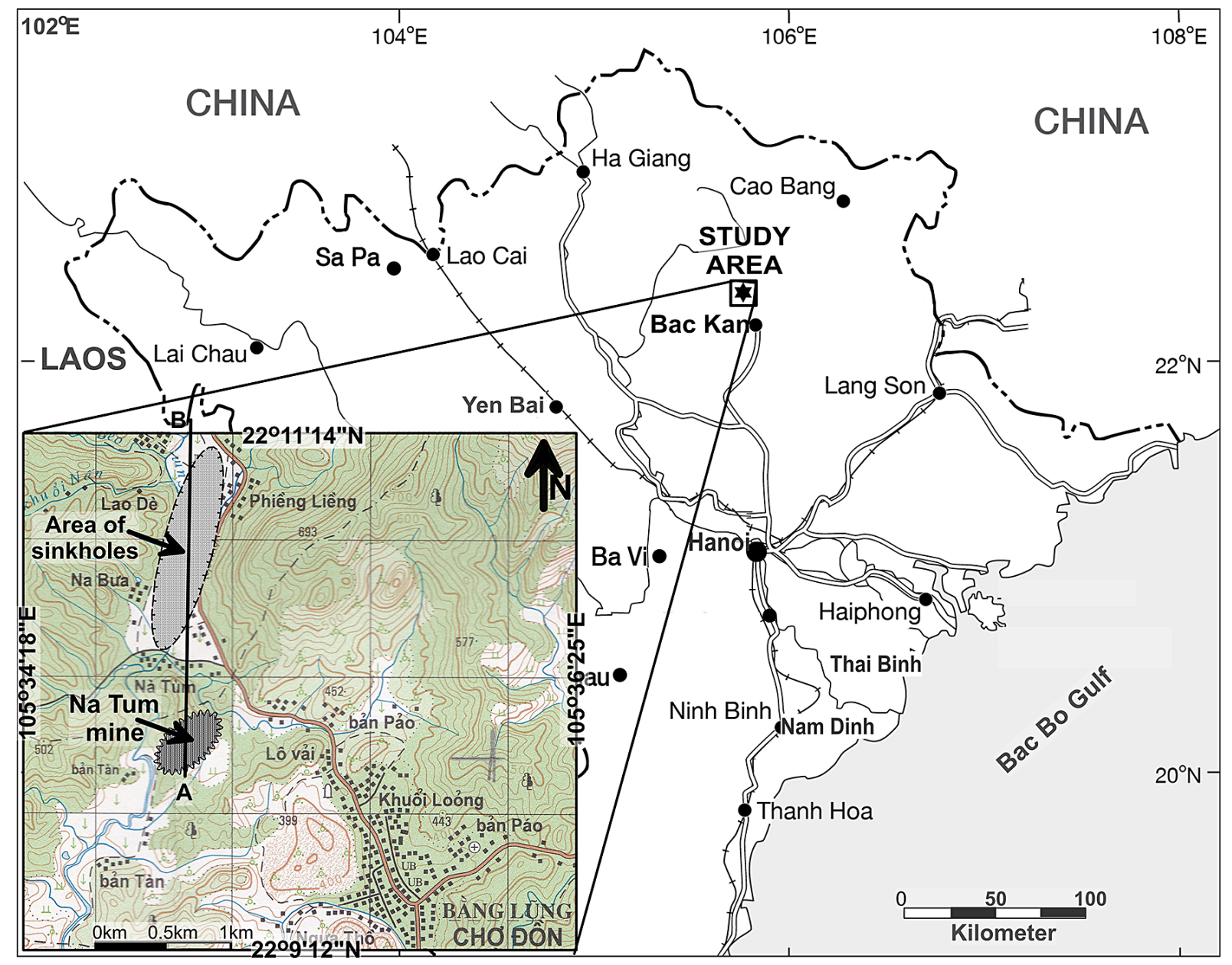

Figure 1. Location map of Na Tum lead-zinc mine and areas of sinkholes.

with large mineral reserves - are in the Bang Lung town of Cho Don, with about 5032 thousand tons of ore [Tran Tuan Anh et al., 2011]. The Na Tum zinc-lead mine in Bang Lung (Figure 1) became functional in April 2007, and sinkhole formations started being reported in some areas around the mine as early as December 2007.

In accordance with the classification by Lowe and Waltham 2002, sinkholes are classified into six types, namely dissolution, collapse, dropout, buried, cap rock, and suffusion sinkholes, depending upon the mechanism of sinkhole formation [Waltham and Fookes, 2003. Notably, most of the sinkholes in the study area are collapse sinkholes, and some are dropout sinkholes. Collapse sinkholes formed entirely within the soil profile area are mainly induced by engineered works, including groundwater (GW) level decline due to GW abstraction or mine dewatering [Waltham, 2008].
Similarly, it is assumed that the formation of collapse sinkholes in the study area is caused due to Na Tum zinc-lead ore mine dewatering.

Groundwater withdrawal has been known to result in sinkhole development in many places around the world. Foose 1953 showed that the Annville stone company had pumped GW at a rate of 19,080 $\mathrm{m}^{3}$ /day for many years before May 1949 in the Hershey valley, part of the Great Valley, Harrisburg, Pennsylvania; notably, no sinkholes were formed. However, when the mine began pumping $35,430 \mathrm{~m}^{3} /$ day in May 1949, the GW level drastically decreased over an area of more than $25 \mathrm{~km}^{2}$, subsequently resulting in most valley springs and wells getting dried up. Ultimately, about 100 sinkholes developed in the area.

In December 1962, a three-storied crusher plant of a gold mine at West Driefontein, west of Johannesburg, South Africa, collapsed into a catas- 


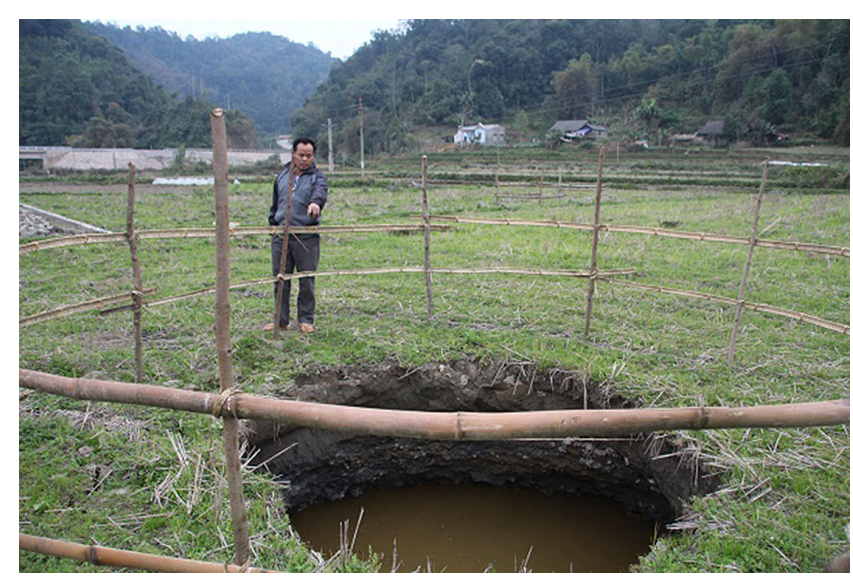

Figure 2. Sinkhole that occurred on the 5th of January 2008 in $\mathrm{Na}$ Bua and Phieng Lieng area (https://moitruong.net.vn/cho-don-bac-kandau-la-nguyen-nhan-gay-sut-lun-nghiem-trong/) .

trophic sinkhole costing twenty-nine lives. The frequency of sinkhole formation in the Transvaal Dolomites increased greatly during 1958-1962 corresponding with a period of a greater GW pumping for underground mining which led to a substantial lowering of the GW level to as much as $120 \mathrm{~m}$ [Jennings et al., 1965.

Land surface collapses in clays and sands of the Talbot formation overlying the Santee karstic limestone aquifer have occurred in the Jamestown area of Berkeley County, South Carolina since the summer of 1975 due to large drop in GW level of more than $114 \mathrm{~m}$ in the Santee aquifer because of pumping $136,275 \mathrm{~m}^{3}$ of GW everyday [Spigner, 1978]. The land surface collapses have caused not only property damage but also casualties.

Sinclair 1982 described that pumping at section 21 well field of Tampa (Florida, United State) municipal well fields at a rate of $18,925 \mathrm{~m}^{3}$ /day since February 1963 and at a rate of $53,000 \mathrm{~m}^{3}$ /day since April 1964 led to the formation of 64 new sinkholes within a $1.61 \mathrm{~km}$ radius of this well field. The South Pasco well field of Tampa municipal well fields began pumping in 1973, because of which more than 30 small sinkholes were identified in 1974 [Sinclair, 1982 .

In accordance with Newton 1986, the investigation of 1981 into sinkhole formations in the eastern United States had identified 6000 sinkholes in 850 sites across 19 states, the costs of damage of which and protective measures against sinkhole formations for certain limited sites were estimated to be about 170 million dollars. The author had em- phasized that GW pumping and water table deepening resulted in sinkhole development by citing many researchers' findings.

Therefore, sinkhole formation in Cho Don can most likely be attributed to the GW decline in Na Tum zinc-lead ore mine despite the strict abidance with the environmental protection standards. The paper also presents an overall hydromechanical analysis to discover the site-specific conditions and the hydromechanism and soil stresses which may have resulted in sinkhole development in the area. The results can be considered essential for developing sinkhole remediation design, for designing preventing measures to avoid sinkhole formations in the future. The results can also prove to be helpful for a comprehensive design to be followed in other relevant mining projects to prevent possible induced sinkhole geohazards.

\section{History of Sinkhole Development in the Study Area}

The Na Tum mine rich in lead-zinc ore reserves was discovered by the "Thai Nguyen" mineral company and became functional in April 2007. The ore body was excavated till a depth of $20 \mathrm{~m}$ by the end of 2007. The pit quarry has a funnel-shaped configuration with an open surface area of about $1000 \mathrm{~m}^{2}$ and a slope from 45 degrees to 60 degrees. Dewatering was required to be carried out for 4-5 days continuously by pumping at a rate of about $35,000 \mathrm{~m}^{3} /$ day, and then at a rate of about $17,500 \mathrm{~m}^{3} /$ day for maintaining a required low water level for ore excavation work. Since 2007, frequent sinkhole formations have been reported in $\mathrm{Na}$ Bua in Phieng Lieng area in the north of Na Tum mine [Vietnam Construction..., 2017] (Figure 1).

The sinkholes are from $1000 \mathrm{~m}$ to $2500 \mathrm{~m}$ from the Na Tum mine to the North (Figure 1). The first sinkhole formed on 12th December 2007, and it had a diameter of about $8 \mathrm{~m}$ and a depth of about $2 \mathrm{~m}$. Following the first sinkhole, a series of sinkholes (10 sinkholes) formed in January 2008, the diameters of which range from $4 \mathrm{~m}$ to $20 \mathrm{~m}$ and the depths from $1.5 \mathrm{~m}$ to $5 \mathrm{~m}$ (Figure 2 and Figure 3). The sinkholes are in the upper range of medium and lower range of large sinkhole sizes as per the classification by Buttrick and Van Schalkwyk 1995. The time of sinkhole formation mostly 


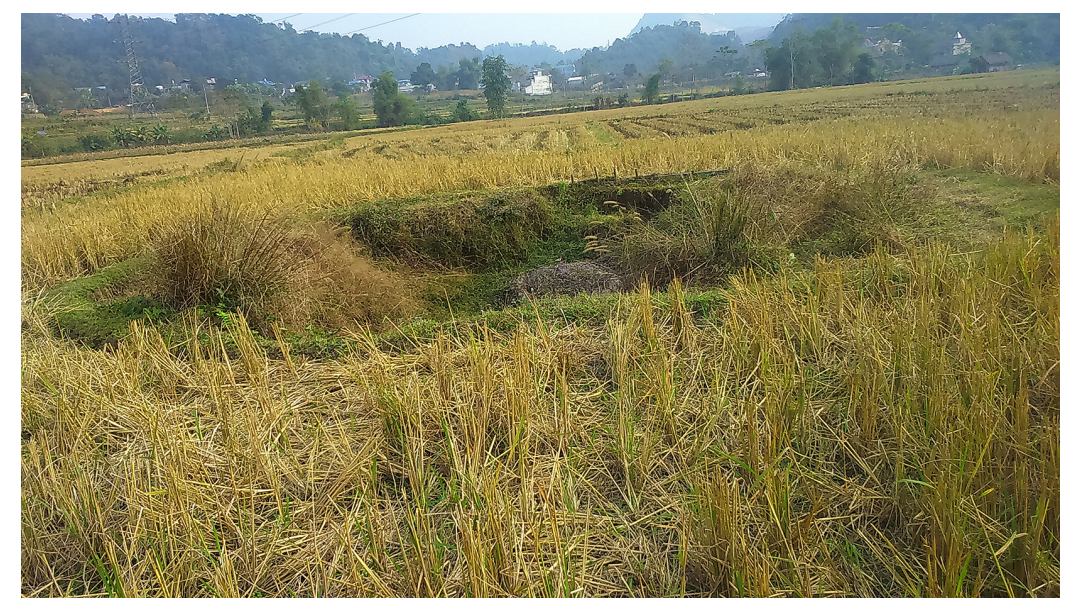

Figure 3. Sinkhole occurred in January 2016 in Na Bua and Phieng Lieng area (photo taken on Dec. 2018).

corresponds with the middle of the dry season (December 2007, January 2008, January 2016, February 2017, December 2018). Figure 4 presents the distribution of sinkholes along with their diameters and depths and also the location of geotechnical bore-hole which provides geotechnical soil log, soil particle graduation data, and some physical and mechanical soil parameters which have been used in this work's analysis.

\section{Geological and Hydrogeological Conditions Related to Sinkhole Formation}

In this section, the geological conditions of a much larger area (Figure 5) which includes Na Bua in Phieng Lieng and the entire Lo Gam structural block will be described. The Lo Gam structural block [Tran Tuan Anh et al., 2011] is bounded by Tong Ba, Phu Ngu structural block in the southeast (Figure 5). From the Vietnam $1: 200,000$ scale geological and mineralogy map [Department of Geology and Minerals of Vietnam, 2005, the information regarding the following geological formations in the area have been derived.

- Phu Ngu formation $\left(\mathrm{O}_{3}-\mathrm{S}_{1} \mathrm{pn}\right)$ is divided into three strata:

- Stratum $1\left(\mathrm{O}-\mathrm{Spn}_{1}\right)$ : mainly consists of shale, siltstone, sandstone with thin layers of cervicitis shale or calcareous siltstone, tuff. Thickness is $1100-1200 \mathrm{~m}$.
- Middle stratum (O-Spn 2$)$ : mainly consists of dark shale, silicate shale, siltstone, sandstone, tuff with lenses of limestone, calcareous siltstone. The thickness is $300 \mathrm{~m}$.

- Stratum $3\left(\mathrm{O}-\mathrm{Spn}_{3}\right)$ : consists of quartz sandstone, quartzite sandstone, hornfels (biotiteandalusite-cordierite). The thickness is $1000 \mathrm{~m}$.

- Lower Devon-Middle Eifeli, Lower Coc Xo formation, upper stratum $\left(\mathrm{D}_{1-2} \mathrm{ecx}_{1}\right)$ : the lower part consists of continuous quartz-sericite shale, sericite shale and sandstone, and quartzite sandstone. The upper part consists of sericite shale with clear foliation, in some places in an unclear band shape, and thin lenses of limestone. The thickness is 200 $500 \mathrm{~m}$.

- Lower Devon-Middle Eifeli, Lower Coc Xo formation, middle stratum $\left(\mathrm{D}_{1-2} \mathrm{ecx}_{2}\right)$ : mainly consists of bedded calcified limestone fossil Favosites, which are interbedded with thin layers or lenses of quartzite sandstone and sericite shale. The thickness is $300-400 \mathrm{~m}$.

- Khao Loc formation - Lower stratum 1 $\left(\mathrm{D}_{1-2} \mathrm{kl}_{1}\right)$ : is available in the southwest of Bang Lung town and consists of sericite shale, quartzite sandstone interbedded with thin layers of limestone. The thickness is $500-600 \mathrm{~m}$.

- Undivided Quaternary formation $(Q)$ : The Quaternary formations are distributed only across the Khau Cum stream valley. The largest area of Quaternary formation distribution is the Khau Cum valley plain and $\mathrm{Na}$ Bua, Phieng Lieng plain, with an area of about $0.6 \mathrm{~km}^{2}$ (Figure 5). The Qua- 


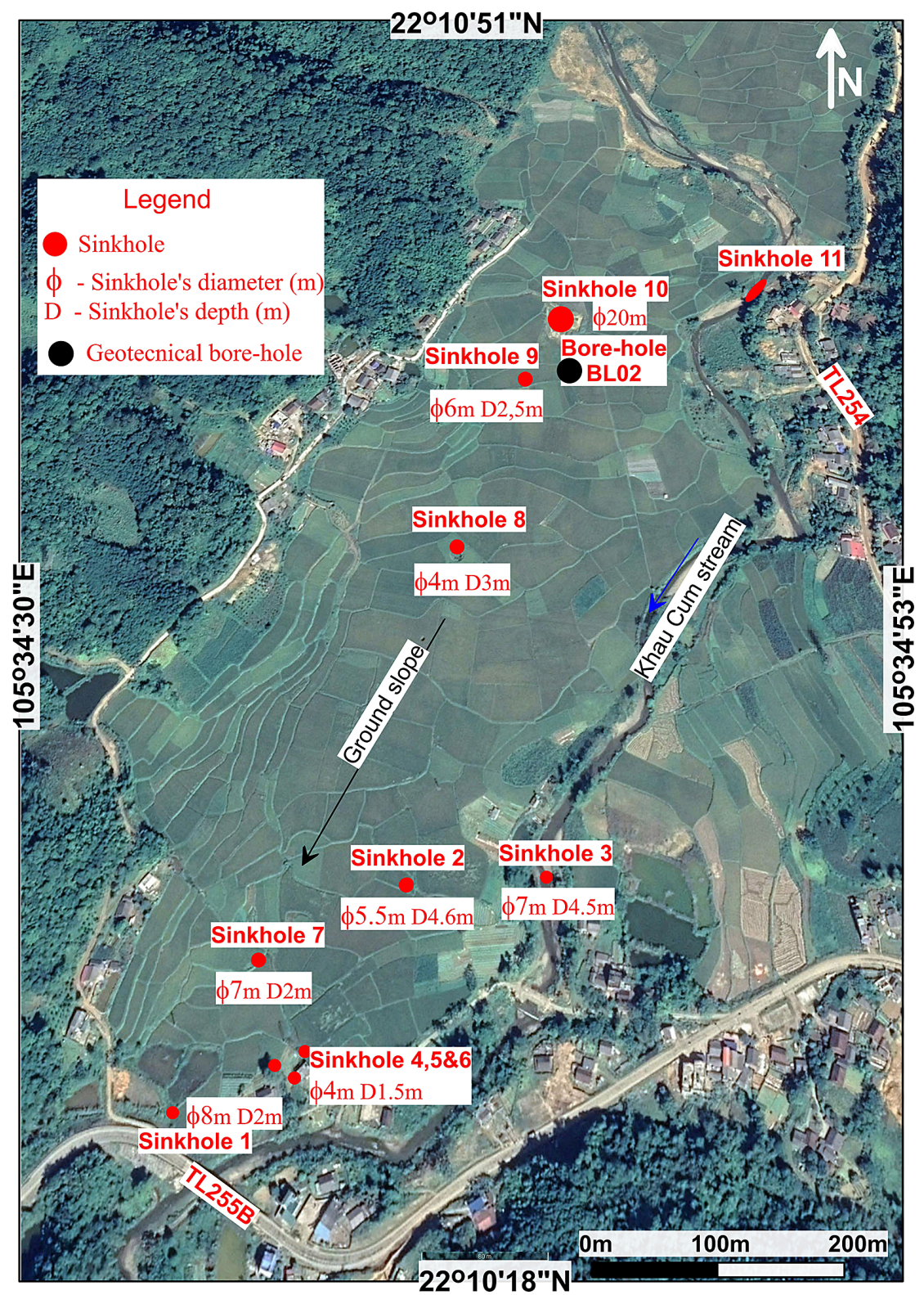

Figure 4. Map of distribution of sinkholes and geotechnical bore-hole.

ternary formations consist of pebble, gravel, sand, and silt or clay. The maximal thickness is about $40 \mathrm{~m}$ in the middle of the plain. The geological map of the study area is presented in Figure 5, in which a cross-section line, $\mathrm{AB}$, through Na Bua, Phieng Lieng area having the sinkhole and Na Tum zinc-lead mine in the direction from downstream to upstream is also shown.

The geotectonic conditions of the area are rather complicated. There are two fault levels in the area, namely the regional deep fault and local faults. The deep regional fault has NE direction and serves as a boundary between Tung Ba, Phu Ngu block in the southeast, and Lo Gam block in the northwest. The local fault system has NE and NW directions. The Coc Xo formation underlying the Quaternary formation is highly fractured in general, and the limestone in the formation is also highly cavernous. The large sinkhole on the provincial road 254 is just on a NW fault, which extends northwest through the middle of the sinkhole in Na Bua, Phieng Lieng. In the area surrounding faults, the rock and soil are highly broken making them highly permeable, which is a favorable con- 


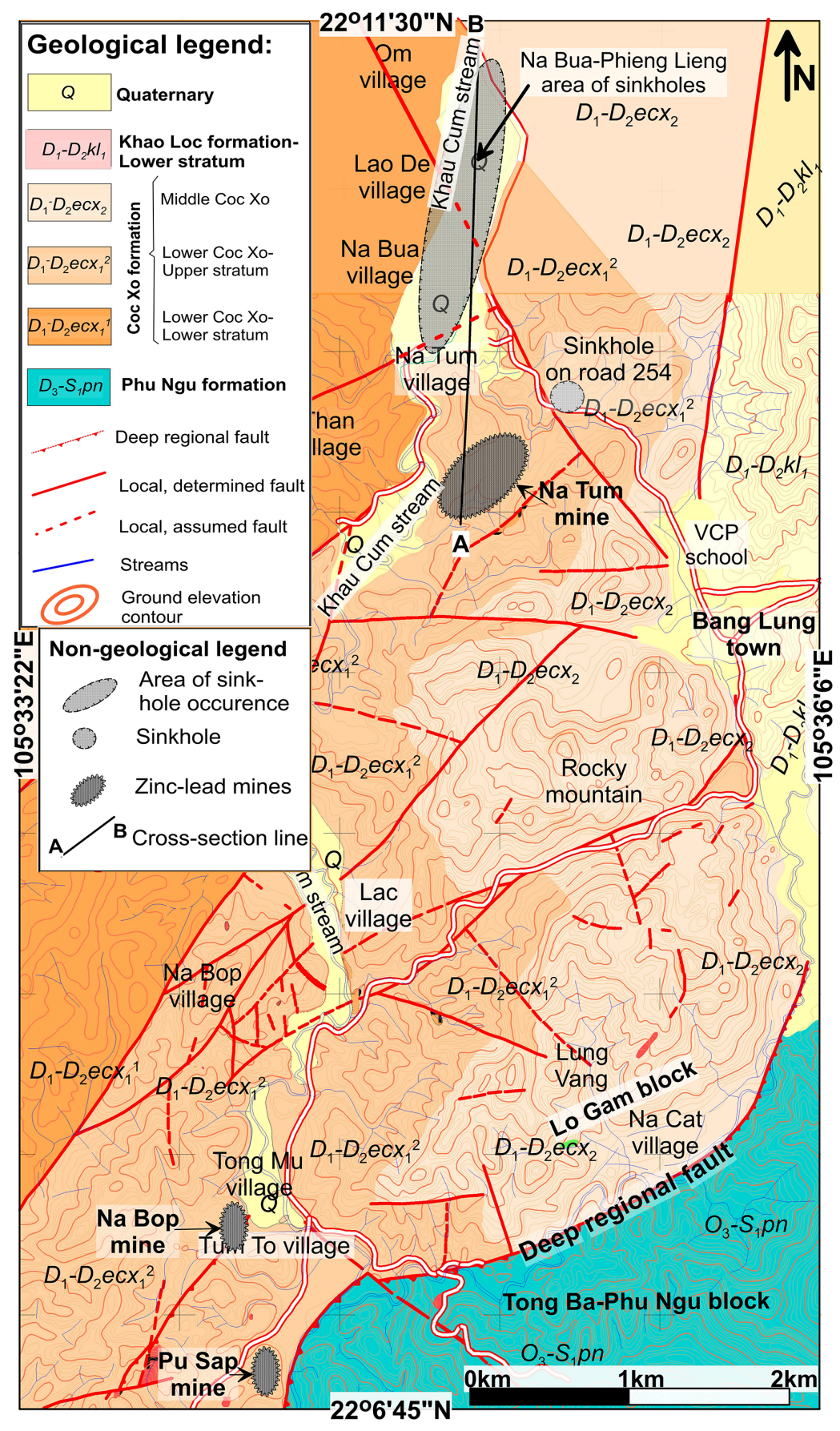

Figure 5. The study area's geological map.

dition for soil suffusion. The drilling survey data collected from the area have shown that cavities exist in the fractured aquifer at different depths, from a depth of $25 \mathrm{~m}$ up to a depth of $70 \mathrm{~m}$, and these are usually filled with silts, sands, and gravels.

In the study area, there exist three aquifers: two unconsolidated aquifers consisting of Quaternary formation (gravel, sand, and silt) and a lower fractured aquifer composed of Coc Xo terrigenous or/and carbonate formation. The two Quaternary aquifers are sand and gravel layer 2 and 3 (hereafter called aquifer 1 and 2, respectively) and karstic bedrock aquifer (hereafter called aquifer 3 ). The aquifer 1 has a thickness of about $15 \mathrm{~m}$ and is overlain by a semi-pervious silt layer 1 of a thickness of about $4.5 \mathrm{~m}$ and overlying the semi-pervious silt 


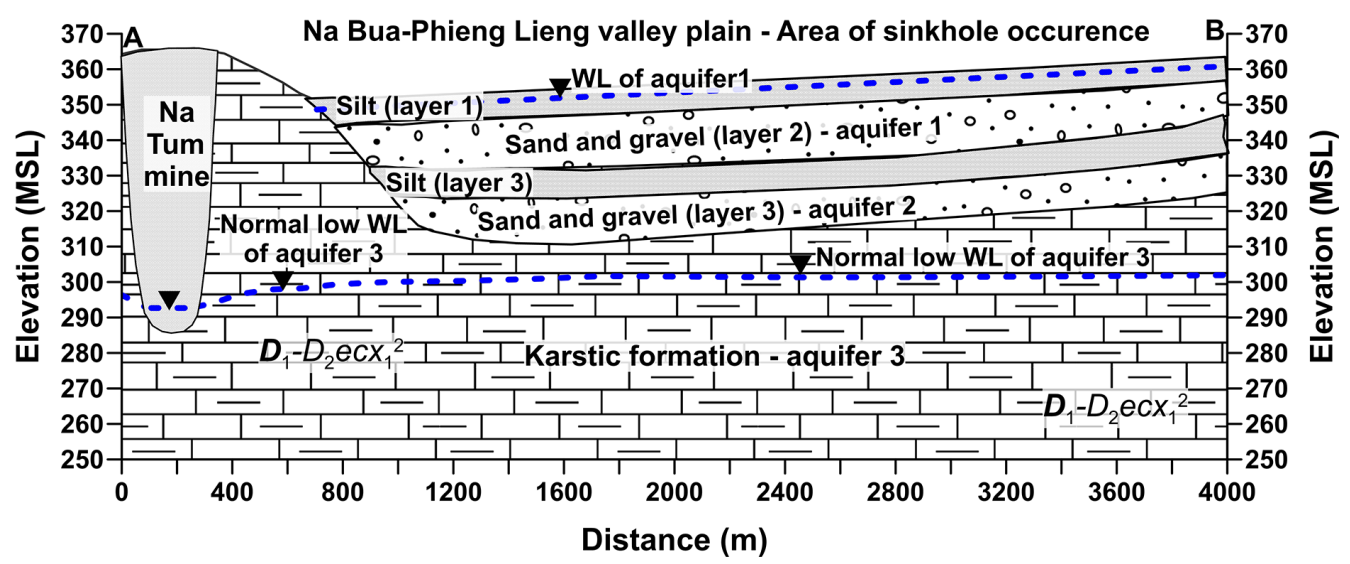

Figure 6. Geological cross-section AB through Na Tum mine and sinkhole area.

layer 3 of a thickness of about $8.5 \mathrm{~m}$. The aquifer 2 has a thickness of about $13 \mathrm{~m}$ and is underlain by the layer 3 and overlying the aquifer 3 (Figure 6$)$.

Rainwater is the main recharge source of the aquifers. The recharge of the aquifer 3 happens through the direct infiltration of rainwater in the mountainous area where the aquifer is exposed to the ground surface. The aquifer 1 is recharged through the infiltration of surface water, rainwater through the semi-pervious layer 1 , and from the aquifer 3 due to the leakage through the semipervious layer 3 . The aquifer 2 is recharged by the leakage from the aquifer 1 and 3 .

The water levels of the aquifers change with the time and are higher during rainy seasons (called high low water level) and lower in dry seasons (called normal low water level in Figure 6).

\section{Hydromechanical Analysis of Sinkhole Development Mechanism}

This section describes the following contents related to sinkhole formation in the study area: Sec. 4.1: the soil suffusion vulnerability criteria by different researchers; Sec. 4.2: the arching failure based on the soil mechanics analysis; Sec. 4.3: the suffusion vulnerability of the soils under study, which shows that the soils are vulnerable to suffusion as defined by different researchers; Sec. 4.3: the favorability of GW conditions of the study site for suffusion of the soil layer above the karstic aquifer; and Sec. 4.5: the sinkhole formation on the ground surface due to the underground arch- ing failure, the diameter of which is quantitatively determined using the soil mechanic analysis.

\subsection{Suffusion Vulnerability Criteria}

There is a distinction between suffusion and suffusion: suffusion is the removal of fine particles by seepage flow from a body of soil without a change in its volume, and suffosion is the removal of fine particles resulting in a contraction of its volume [Riha et al., 2019]. In this section, subsurface erosion is used for avoiding the exact context of suffusion or suffosion. However, the term suffusion is still used in some places in this paper to reflect the researchers' original use.

Soil porosity: As a rule, the larger the soil porosity, the more is the soil's vulnerability to subsurface erosion. There are some subsurface erosion criteria involving soil porosity parameters. Therefore, the porosity of the soil samples needs to be determined. Urumović and Urumović 2016 proposed a general mathematical expression for calculating the geometric particle size diameter, $D_{g}$, of non-cohesive soils, which is used for estimation of specific yield and permeability:

$$
\begin{gathered}
D_{g}=\exp \left[0.01 \sum P_{i} \ln \left(d_{i, g}\right)\right], \\
d_{i, g}=\sqrt{d_{i<} \times d_{i>}},
\end{gathered}
$$

in which $P_{i}$ is the percentage of passing diameter $d_{i>}, d_{i<}$ is the smallest particle diameter, and $d_{i>}$ is the largest particle diameter in the segment passing $P_{i}$. 


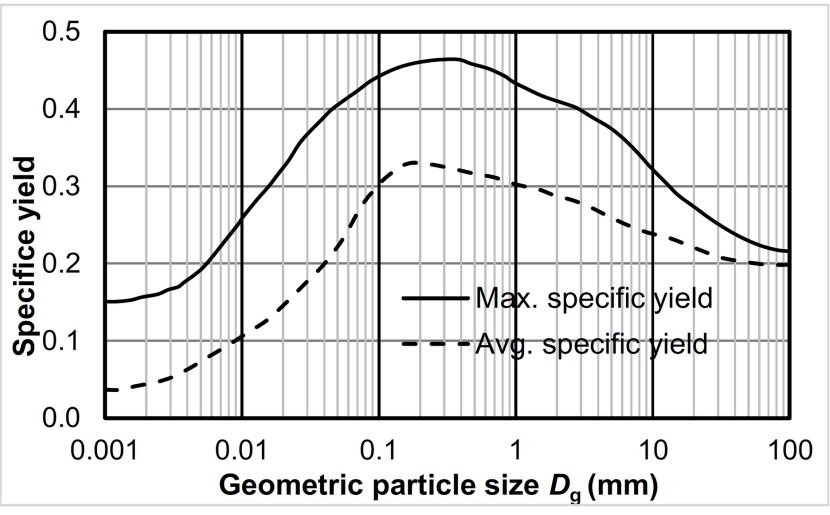

Figure 7. Relationship between geometric particle size and specific yield (rebuilt from [Urumović and Urumović, 2016).

The authors have constructed curves expressing the relationship between geometric particle size $D_{g}$ and maximal, average and minimal values of the specific yield of 586 soil samples (33 samples of gravel, 287 of sand, and 266 of silt and clay) (Figure 7) from the data collected by Morris and Johnson [1967]. The total porosity is then calculated as equal to the summation of specific yield, water retention, and centrifuge moisture. In this work, for coarse sand and gravel, mean water retention and centrifuge moisture to be used are 0.07 and 0.03 , respectively [Morris and Johnson, 1967].

The following geometric criteria reported by different researchers have been used to assess the susceptibility of soils to subsurface erosion:

Istomina's criterion: Suffusion may occur within a soil layer which is highly non-uniform or from a layer of smaller grains to a layer of larger grains. Istomina 1957] [refer to Lomtadze, 1977 carried out suffusion experiments with soils with different soil uniformity coefficients $\left(C_{u}=\right.$ $\left.d_{60} / d_{10}\right)$ and stated the relationship between $C_{u}$ and suffusion-gradient as shown in Figure 8.

Kenney and Lau's criterion: Kenney and Lau 1985 carried out constant-head permeameter tests on 16 well-graded sandy gravels. The soil was reconstituted by compaction in a cylindrical cell, forming a specimen with a diameter of either $245 \mathrm{~mm}$ or $580 \mathrm{~mm}$ and length of either $450 \mathrm{~mm}$ or $860 \mathrm{~mm}$. A low surcharge pressure of $10 \mathrm{kPa}$ (1 m of water column) was applied with a downward seepage flow at a gradient of 1.16 or 2.22 . The authors' criterion is based on the shape of the grain-size distribution curves. The increment of the percent passing $(H)$ that occurs over the designated grain-size interval from $d$ to $4 d$ is compared with the percent passing $(F)$ at the grain size $d$. Kenney and Lau proposed that the particles finer than $d$ (having a mass fraction $F$ ) would likely erode from the soil if there were not enough particles in the grain sizes ranging from $d$ to $4 d$ (having a mass fraction $H$ ). Further, $H / F$ can be obtained from the grain-size distribution curve over the portion of its finer fraction given by $F \leq 20 \%$ for the soils with a broadly-graded primary fabric $\left(C_{u}>3\right)$ and by $F \leq 30 \%$ for the soils with a narrowly-graded primary fabric $\left(C_{u} \leq 3\right)$. Later, Kenney and Lau 1986 revised this criterion and proposed that if $(H / F)_{\min }>1$, then the soil is classified as internally stable:

- For $C_{u}>3: F>20 \%$ and $H / F \leq 1.0$, the soil is unstable.

- For $C_{u} \leq 3: F>30 \%$ and $H / F \leq 1.0$, the soil is unstable.

Burenkova's criterion: Burenkova 1993 proposed a method based on the results of laboratory tests on 22 granular materials, with the maximum particle sizes up to $100 \mathrm{~mm}$, and the coefficient of uniformity, $C_{u}$, up to 200 . The basic assumption is that a smaller size fraction does not form a part of the basic soil skeleton if it does not cause a volume increase when mixed with a coarser size fraction. Based on the three representative fractions, $d_{15}, d_{60}$, and $d_{90}$, the heterogeneity of the soils was described by two ratios, which are called conditional factors of uniformity:

$$
0.76 \log \left(h^{\prime \prime}\right)+1<h^{\prime}<1.86 \log \left(h^{\prime \prime}\right)+1
$$

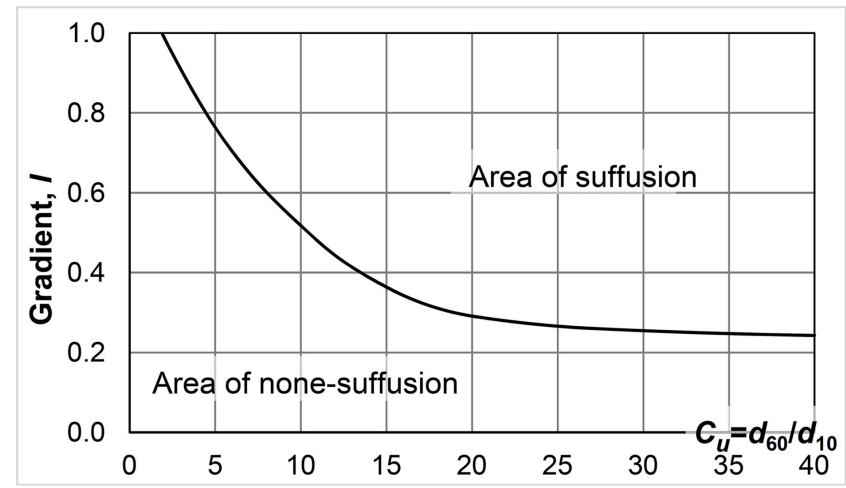

Figure 8. Suffusion, by Istomina 1957 (redrawn from [Lomtadze, 1977]). 
where $h^{\prime}=d_{90} / d_{60}$ and $h^{\prime \prime}=d_{90} / d_{15}, d_{90}, d_{60}$, and $d_{15}$ are the diameters $(\mathrm{mm})$ corresponding to $90 \%$, $60 \%$, and $15 \%$ mass passing, respectively.

Kezdi's criterion: Kezdi 1975 proposed a method to assess the internal stability of soils as follows. The grain-size curve is split into its coarse and fine components at an arbitrary reference grain diameter $d$; the coarser component may be evaluated for its capacity to retain the finer component. The soil is considered as unstable if $D_{15} / d_{85}>4$, where $D_{15}$ is the diameter of the $15 \%$ mass passing in the coarser fraction, and $\mathrm{d} 85$ is the diameter of the $85 \%$ mass passing in the finer fraction.

Liu's criterion: Liu 2005 described a method proposed by himself in 1963 to assess the internal stability of non-cohesive soils [refer to $\mathrm{Li}$, 2008. The fundamental of the method is the division of soil particles into two components: a finer fraction and a coarser fraction. The soil is considered to be internally stable if the finer particles fully occupy the void spaces formed by the coarser particles. The author, using theoretical analysis and experimental results, proposed the following criterion based on the ratio $P$ between the finer mass passing and the coarser mass passing at the gap location for the gap-graded soils or the division diameter, $d_{f}=\sqrt{d_{70} d_{10}}$ :

$-P<25$ - internally unstable,

$-P=25$ to 35 - transition condition,

$-P>35$ - internally stable.

Mao's criterion: Similar to Liu's method proposed in 1963, Mao, in 1981 [refer to Mao, 2005 , suggested the utilization of the porosity $(n)$ and the division diameter for continuously graded soils [refer to $L i, 2008$ :

$$
\begin{gathered}
P_{f}<100\left[\frac{1}{4(1-n)}\right]-\text { internally unstable, } \\
P_{f} \geq 100\left[\frac{1}{4(1-n)}\right]-\text { internally stable. }
\end{gathered}
$$

Busch and Luckner's criterion: Busch and Luckner 1972 [refer to Hudak, 2009 proposed that the particles less than or equal to $d_{s}$ defined as follows can undergo subsurface erosion:

$$
d_{s}=0.27 \sqrt[6]{C_{u} \varepsilon d_{17}}
$$

where $d_{s}$ is the largest grain that can undergo suffusion (mm), $C_{u}$ is the coefficient of uniformity; $\varepsilon$ is the void ratio, and $d_{17}$ is the diameter $(\mathrm{mm})$ corresponding to $17 \%$ mass passing.

Patrasev's criterion: Patrasev 1957] [refer to Semar et al., 2010, in his study for selection of graduation materials used in the reverse filters, proposed that the particles less than or equal to $d_{s}$ defined as follows can undergo subsurface erosion:

$$
\begin{gathered}
d_{s}=0.77 d_{p o}, \\
d_{p o}=0.455\left(1+0.05 C_{u}\right) \times \\
\sqrt[6]{C_{u} \varepsilon d_{17}} \quad \text { for } C_{u} \leq 25, \\
d_{p o}=0.16\left(3+\sqrt[3]{C_{u} \log C_{u}}\right) \times \\
\sqrt[6]{C_{u} \varepsilon d_{17}} \quad \text { for } C_{u}>25,
\end{gathered}
$$

where $d_{s}$ is the largest suffusive grain size diameter (in $\mathrm{mm}$ ), and $d_{p o}$ is the effective opening size of the structure (in $\mathrm{mm}$ ).

Ziems's criterion: Ziem [1969] [refer to Semar et al.,2010 proposed that the particles with a size less than or equal to $d_{s}$ defined as follows can undergo subsurface erosion:

$$
d_{\min }=0.409 \sqrt[6]{C_{u} e d_{17}},
$$

where $d_{\text {min }}$ is the largest suffusive grain size diameter (mm).

\subsection{Sinkhole Formation due to Soil Arching Failure}

Collapse sinkholes mostly result due to soil arching failure. The soil mechanic fundamentals regarding soil arching are explained well by Terzaghi 1943.

Suppose there is a soil arching situation described in Figure 9, the soil vertical stress $\sigma_{h, z}$ without overlying load can be derived using the loose pressure theory proposed by Terzaghi 1943 and improved by Kezdi 1975 for a circular cavern with a diameter $D$ :

$$
\sigma_{v, Z}=\frac{D \gamma-4 c}{4 \tan \phi}\left(1-e^{-4 K \tan \phi \frac{Z}{D}}\right)
$$




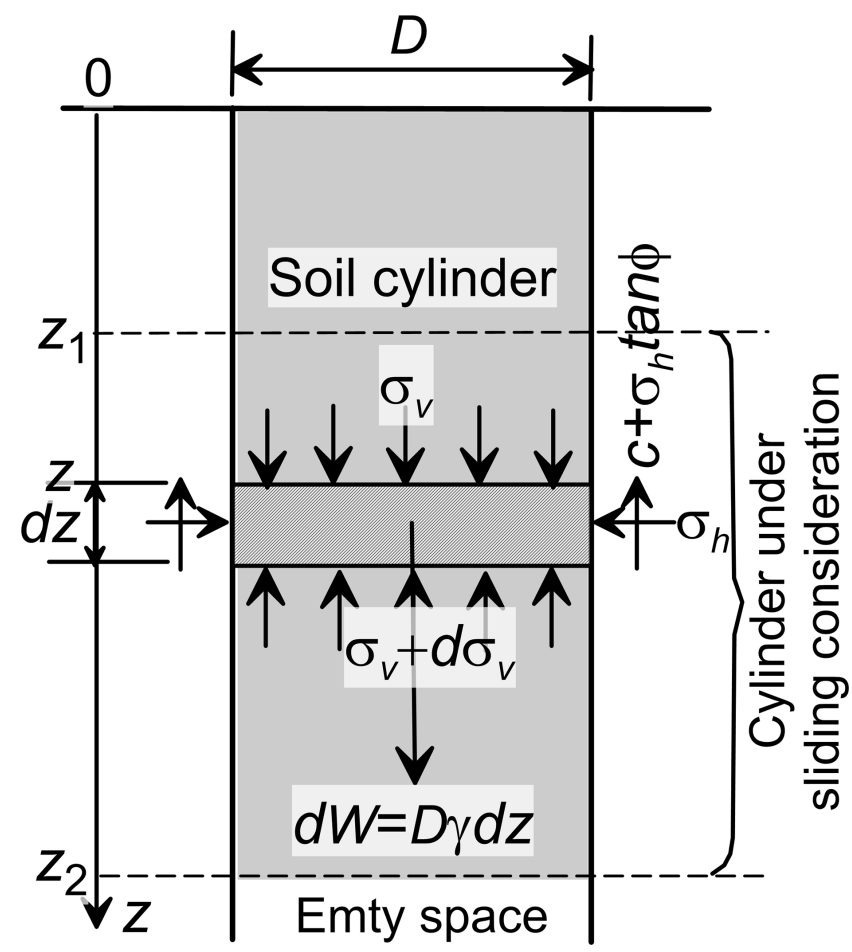

Figure 9. Soil arching analysis (redrawn from [Terzaghi, 1943]).

where $K$ is the lateral earth pressure coefficient, $Z$ is the depth, and $\phi$ is the angle of internal friction.

Along the vertical cylinder surface with the diameter $D$ the normal stress $\sigma_{r, z}$ to the cylinder surface at depth $z$ is $\sigma_{r, z}=c+\sigma_{h, z} \tan \phi$. Therefore, the total sliding resistance $R$ of the cylinder from depth $z_{1}$ to $z_{2}$ is:

$$
R=\frac{\pi D^{2}}{4} c+\pi D \int_{z_{1}}^{z_{2}}\left(c+\sigma_{h, z} \tan \phi\right) d z,
$$

in which: the first part is thanks to the total soil cohesion over the upper cylinder end at $z_{1}$.

The weight $W$ of the soil cylinder is $W=\pi D\left(z_{2}-\right.$ $\left.z_{1}\right) \gamma$. Let us denote the safety factor of sliding as $F S_{\text {sliding }}$ equal to the ratio between total sliding resistance $R$ and the weight $W$ :

$$
\begin{gathered}
F S_{\text {sliding }}=\frac{R}{W}=\frac{1}{4\left(z_{2}-z_{1}\right) \gamma} \times \\
{\left[c D+\int_{z_{1}}^{z_{2}}\left(c+K \sigma_{h, z} \tan \phi\right) d z\right] .}
\end{gathered}
$$

Notably, sliding failure of the soil cylinder occurs when $F S_{\text {sliding }}$ is less than unity.

\subsection{Suffusion Vulnerability Analysis Results}

The soil samples of the two layers of sand and gravel (the layer 2 and 4) have been taken from bore-hole BL02 in the middle of Na Bua, Phieng Lieng valley plain, where most of the sinkholes formed. The particle size distribution data show that all the soil samples are continuously graded, for which Mao's suffusion criterion is applicable and can be used in our study.

The analysis results in accordance with the abovedescribed suffusion criteria are summarized as follows.

Istomina's criterion: The results presented in Figure 10 show that the critical gradient for suffusion of the soil under consideration is mostly equal to 0.2 and the maximal critical gradient of 0.725 is for the sample having $C_{u}$ equal 2.4. It means that suffusion may occur continuously over a long period, from a year of less hydrodynamics, during which the finer particles are eroded, to a year of higher hydrodynamics, during which the coarser particles are eroded.

Kenney and Lau criterion: In accordance with this criterion, the particles finer than 0.0075 $\mathrm{mm}$ would not likely erode from the soil. Two samples are internally unstable for the particles finer than $0.03 \mathrm{~mm}$, which are along with other 7 samples internally unstable for the particles finer than

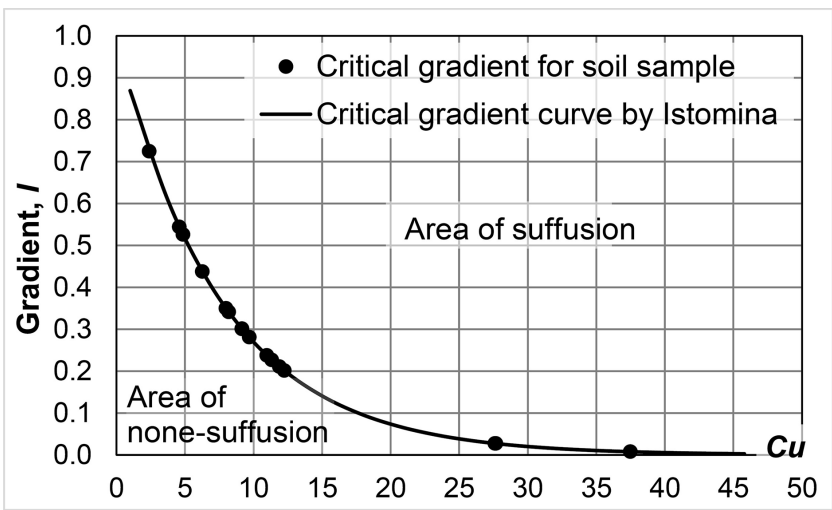

Figure 10. Study soil subsurface erosion by Istomina. 
Table 1. Analysis Results in Accordance With Kenney and Lau's Criterion

\begin{tabular}{|c|c|c|c|c|c|c|c|}
\hline \multirow{3}{*}{$\begin{array}{c}\text { Soil } \\
\text { sample } \\
\text { number }\end{array}$} & \multicolumn{7}{|c|}{ Maximal of erodible particle diameter (mm) } \\
\hline & 0.005 & 0.0075 & 0.030 & 0.075 & 0.20 & 0.40 & 1.30 \\
\hline & \multicolumn{7}{|c|}{ Internal stable (Stab.) or unstable (Uns.) } \\
\hline 1 & Stab. & Stab. & Stab. & Stab. & Stab. & Uns. & Uns. \\
\hline 2 & Stab. & Stab. & Stab. & Stab. & Stab. & Stab. & Uns. \\
\hline 3 & Stab. & Stab. & Stab. & Stab. & Stab. & Uns. & Uns. \\
\hline 4 & Stab. & Stab. & Stab. & Stab. & Stab. & Uns. & Uns. \\
\hline 5 & Stab. & Stab. & Stab. & Uns. & Uns. & Uns. & Uns. \\
\hline 6 & Stab. & Stab. & Stab. & Uns. & Uns. & Uns. & Uns. \\
\hline 7 & Stab. & Stab. & Uns. & Uns. & Uns. & Uns. & Uns. \\
\hline 8 & Stab. & Stab. & Uns. & Uns. & Uns. & Uns. & Uns. \\
\hline 9 & Stab. & Stab. & Stab. & Uns. & Uns. & Uns. & Uns. \\
\hline 10 & Stab. & Stab. & Stab. & Uns. & Uns. & Uns. & Uns. \\
\hline 11 & Stab. & Stab. & Stab. & Stab. & Uns. & Uns. & Uns. \\
\hline 12 & Stab. & Stab. & Stab. & Stab. & Uns. & Uns. & Uns. \\
\hline 13 & Stab. & Stab. & Stab. & Stab. & Uns. & Uns. & Uns. \\
\hline 14 & Stab. & Stab. & Stab. & Uns. & Uns. & Uns. & Uns. \\
\hline 15 & Stab. & Stab. & Stab. & Stab. & Uns. & Uns. & Uns. \\
\hline 16 & Stab. & Stab. & Stab. & Stab. & Uns. & Uns. & Uns. \\
\hline $17^{*}$ & Stab. & Stab. & Stab. & Stab. & Uns. & Uns. & Uns. \\
\hline
\end{tabular}

* Soil sample number 17 is the average of the 16 samples.

$0.075 \mathrm{~mm} .12$ the samples are internally unstable for particles finer than $0.2 \mathrm{~mm}$. Almost all the samples are internally unstable for particles finer than $0.4 \mathrm{~mm}$ (Figure 11). Table 1 summarizes the soil internal instability or stability in terms of the maximal particle diameter of particles that are vulnerable to erosion. Since almost all the soil samples are internally instable for the particles finer than $0.4 \mathrm{~mm}$, the soil is considered as internally instable.

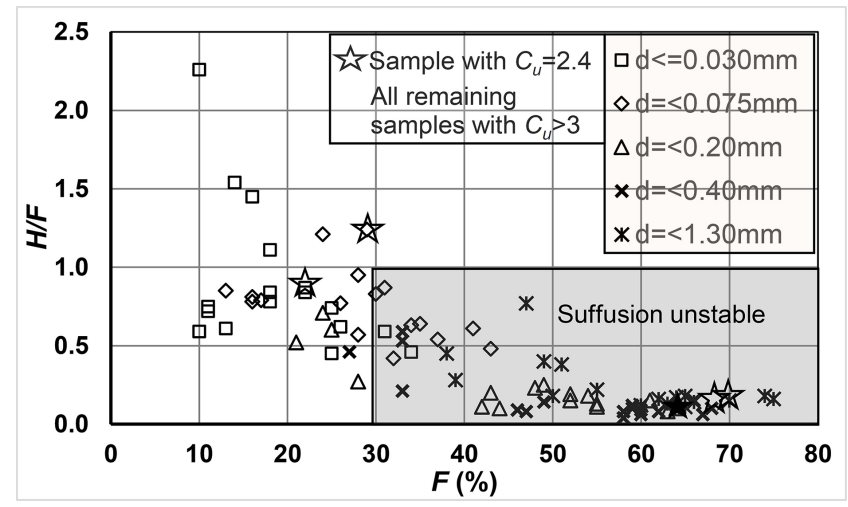

Figure 11. Study soil suffusion instability according to Kenney and Lau's criterion (1986).
Burenkova's criterion: The analysis results for the soil under consideration are presented in Figure 12, where most of the soil samples are suffusion unstable and only a few samples are internally stable.

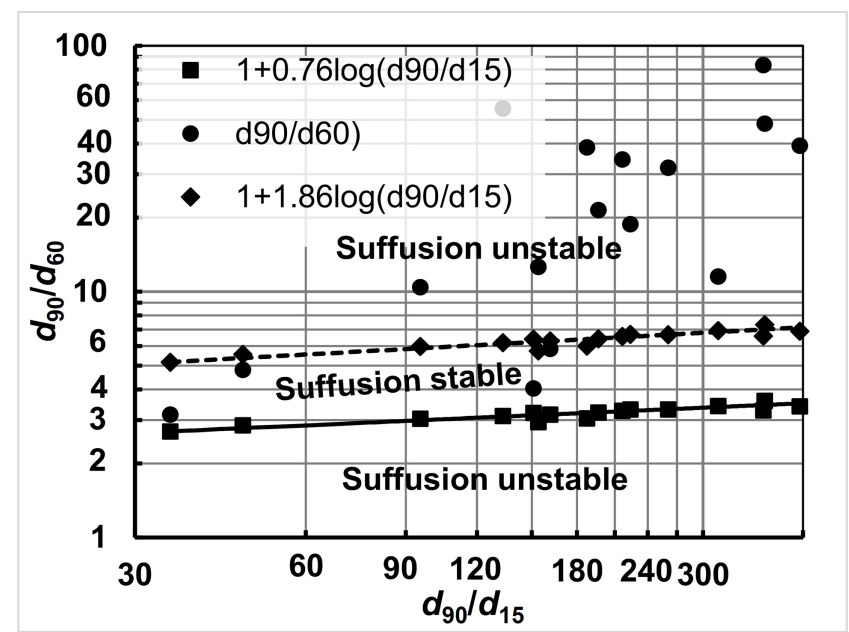

Figure 12. Study soil suffusion internal instability in accordance with Burenkova's criterion. 


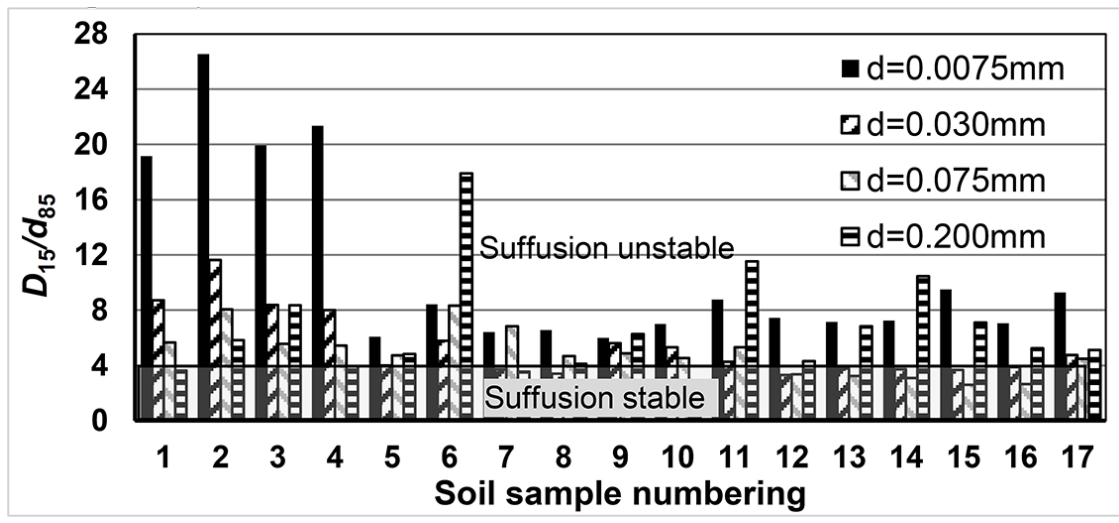

Figure 13. Study soil suffusion instability in accordance with Kenney and Lau' criterion (1986).

Table 2. Results of Internal Stability of the Soil Sample in Accordance With Mao's Criterion

\begin{tabular}{|c|c|c|c|c|c|c|c|}
\hline \multirow{3}{*}{$\begin{array}{c}\text { Soil } \\
\text { sample } \\
\text { number }\end{array}$} & \multicolumn{4}{|c|}{ Average porosity } & \multicolumn{3}{|c|}{ Maximal porosity } \\
\hline & & & Suffusion & & & Suffusion & $P_{f}$ by \\
\hline & $n$ & $\frac{100}{4(1-n)}$ & Stab./Uns. & $n$ & $\frac{100}{4(1-n)}$ & Stab./Uns. & Mao (1981) \\
\hline 1 & 0.42 & 43.1 & Stab. & 0.55 & 55.2 & Uns. & 50.9 \\
\hline 2 & 0.41 & 42.3 & Uns. & 0.53 & 53.4 & Uns. & 40.4 \\
\hline 3 & 0.40 & 41.7 & Uns. & 0.54 & 53.8 & Uns. & 40.6 \\
\hline 4 & 0.42 & 42.9 & Uns. & 0.56 & 56.7 & Uns. & 42.2 \\
\hline 6 & 0.42 & 43.3 & Stab. & 0.56 & 57.4 & Uns. & 47.8 \\
\hline 9 & 0.44 & 44.5 & Stab. & 0.57 & 58.2 & Uns. & 58.0 \\
\hline 11 & 0.43 & 43.8 & Stab. & 0.57 & 58.1 & Uns. & 46.1 \\
\hline 17 & 0.43 & 44.1 & Stab. & 0.56 & 57.2 & Uns. & 52.2 \\
\hline
\end{tabular}

Kezdi's criterion: For each of the samples, four arbitrary reference grain diameters d have been used to divide the sample into two components of coarse and fine fractions. The calculation

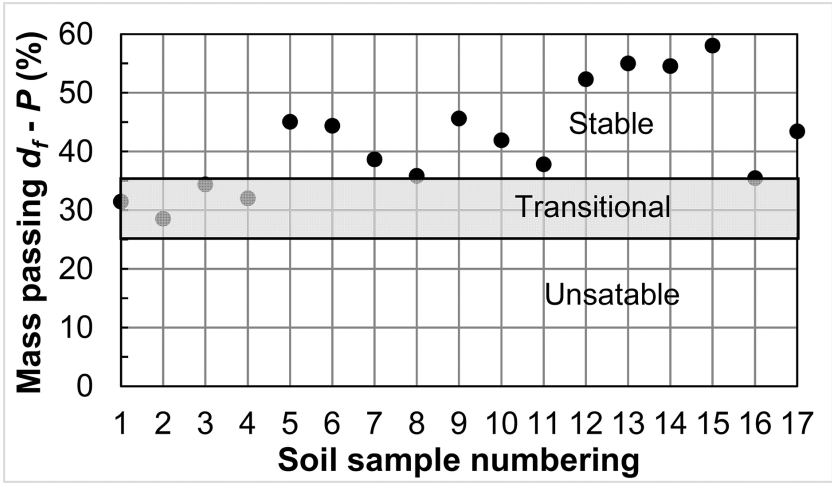

Figure 14. Study soil suffusion instability in accordance with Kenney and Lau's criterion (1986). results of all the soil samples have allowed building a graphical presentation, as shown in Figure 13. The results show that most of the samples are susceptible to subsurface erosion. However, two samples are not susceptible to subsurface erosion for the reference grain size of $0.03 \mathrm{~mm}$. Five samples are not susceptible to subsurface erosion for the reference grain size $0.075 \mathrm{~mm}$. Four samples are not susceptible to subsurface erosion for the reference grain size $0.2 \mathrm{~mm}$.

Liu's criterion: The analysis results have been presented in Figure 14, which shows that most of the soil samples are internally unstable and the remaining five samples are transitionally instable.

Mao's criterion: With the average and maximal porosity of the soil samples determined by the statistical data by Morris and Johnson 1967, the internal instability of the soil samples was determined by the criterion given by Mao 1981. The detailed analysis results are presented in Table 2. 
Table 3. Results of Internal Stability in Accordance in With Accordance With Busch and Luckner's, Patrasev's, and Ziem's criteria

\begin{tabular}{|c|c|c|c|c|c|c|c|c|}
\hline \multirow[b]{2}{*}{$\begin{array}{l}\text { Sample } \\
\text { number }\end{array}$} & \multirow[b]{2}{*}{$n$} & \multicolumn{3}{|c|}{ Average porosity } & \multicolumn{4}{|c|}{ Maximal porosity } \\
\hline & & $\begin{array}{c}\text { By Busch \& } \\
\text { Luckner } \\
D_{s}(\mathrm{~mm})\end{array}$ & $\begin{array}{c}\text { By } \\
\text { Patrasev } \\
d_{p o}(\mathrm{~mm})\end{array}$ & $\begin{array}{c}\text { By } \\
\text { Ziem } \\
d_{\text {min }}(\mathrm{mm})\end{array}$ & $n$ & $\begin{array}{c}\text { By Busch \& } \\
\text { Luckner } \\
D_{s}(\mathrm{~mm})\end{array}$ & $\begin{array}{c}\text { By } \\
\text { Patrasev } \\
d_{p o}(\mathrm{~mm})\end{array}$ & $\begin{array}{c}\text { By } \\
\text { Ziem } \\
d_{\min }(\mathrm{mm})\end{array}$ \\
\hline 1 & 0.41 & 0.2464 & 0.4659 & 0.3732 & 0.54 & 0.2683 & 0.5075 & 0.4065 \\
\hline 2 & 0.40 & 0.2646 & 0.5096 & 0.4008 & 0.52 & 0.2873 & 0.5534 & 0.4352 \\
\hline 3 & 0.39 & 0.2977 & 0.9365 & 0.4510 & 0.53 & 0.3262 & 1.0261 & 0.4942 \\
\hline 4 & 0.41 & 0.2525 & 0.5073 & 0.3825 & 0.55 & 0.2778 & 0.5582 & 0.4209 \\
\hline 5 & 0.43 & 0.1732 & 0.3146 & 0.2623 & 0.56 & 0.1889 & 0.3431 & 0.2861 \\
\hline 6 & 0.41 & 0.2492 & 0.9727 & 0.3775 & 0.55 & 0.2741 & 1.0700 & 0.4152 \\
\hline 7 & 0.41 & 0.1545 & 0.2826 & 0.2340 & 0.54 & 0.1691 & 0.3092 & 0.2561 \\
\hline 8 & 0.40 & 0.1519 & 0.2589 & 0.2301 & 0.54 & 0.1665 & 0.2839 & 0.2522 \\
\hline 9 & 0.43 & 0.1900 & 0.3932 & 0.2878 & 0.56 & 0.2076 & 0.4296 & 0.3145 \\
\hline 10 & 0.43 & 0.1920 & 0.3632 & 0.2908 & 0.56 & 0.2094 & 0.3962 & 0.3171 \\
\hline 11 & 0.42 & 0.2438 & 0.7136 & 0.3693 & 0.56 & 0.2679 & 0.7841 & 0.4058 \\
\hline 12 & 0.43 & 0.2118 & 0.4305 & 0.3208 & 0.56 & 0.2321 & 0.4718 & 0.3515 \\
\hline 13 & 0.42 & 0.1924 & 0.3071 & 0.2915 & 0.56 & 0.2123 & 0.3388 & 0.3215 \\
\hline 14 & 0.42 & 0.1891 & 0.3050 & 0.2864 & 0.56 & 0.2076 & 0.3348 & 0.3145 \\
\hline 15 & 0.42 & 0.2379 & 0.4975 & 0.3603 & 0.56 & 0.2615 & 0.5469 & 0.3961 \\
\hline 16 & 0.43 & 0.1561 & 0.2269 & 0.2365 & 0.56 & 0.1706 & 0.2479 & 0.2584 \\
\hline 17 & 0.42 & 0.2445 & 0.7160 & 0.3704 & 0.55 & 0.2668 & 0.7813 & 0.4041 \\
\hline
\end{tabular}

The results show that $50 \%$ and $18 \%$ (3 samples) of the samples are internally unstable for maximal porosity values and mean porosity values, respectively.

Busch and Luckner's, Patrasev's, and Ziem's criteria: The largest particle sizes of the soil samples under consideration that are subject to subsurface erosion determined by Busch and Luckner, Patrasev, and Ziem criteria are presented in Table 3. On an average, the maximal particle sizes which are susceptible to subsurface erosion, according to Busch \& Luckner, Ziem, and Patrasev, are $0.245 \mathrm{~mm}, 0.370 \mathrm{~mm}$, and $0.716 \mathrm{~mm}$, respectively, for the largest average porosity, and $0.267 \mathrm{~mm}$, $0.781 \mathrm{~mm}$, and $0.404 \mathrm{~mm}$, respectively, for the maximal porosity. The ratios between the particle sizes by the three authors are $1: 1.5: 2.9$.

\subsection{Groundwater Hydraulic Conditions}

As it was described at the end of section 3 , before dewatering the Na Tum mine for ore exploitation, all the three aquifers were confined, with water levels more or less the same due to long-term inter- action through leakage through the semi-pervious layers between the aquifers. However, presently the mine depth is about $80 \mathrm{~m}$ (which is corresponding to absolute elevation is $285 \mathrm{~m}$ above mean sea level - MSL) the dewatering of the mine has caused the total water level drawdown of about $70 \mathrm{~m} \mathrm{(290}$ MSL). From the GW well hydraulic fundamentals, the GW level drawdown at any time counted from the beginning of GW dewatering, when the pumping is long enough, would reach equilibrium and is proportional to the natural logarithm of the distance from the center of the mine pit quarry under dewatering [Thiem, 1906, refer to Fetter, 2001. Figure 6 above depicts the GW level at present (named as normal low water level), showing that a very large water level drawdown occurred over a very long distance of several thousand meters.

Let us consider the hydraulic conditions of aquifer 3 in relation to suffusion. During the dry seasons, the water level is lower (normal low water level in Figure 6 than the bottom of aquifer 2. This downward vertical water flow with a unity gradient in aquifer 3 in combination with the above-identified suffusion vulnerability certainly results in the suffusion of soil particles from aquifer 2 into karstic 


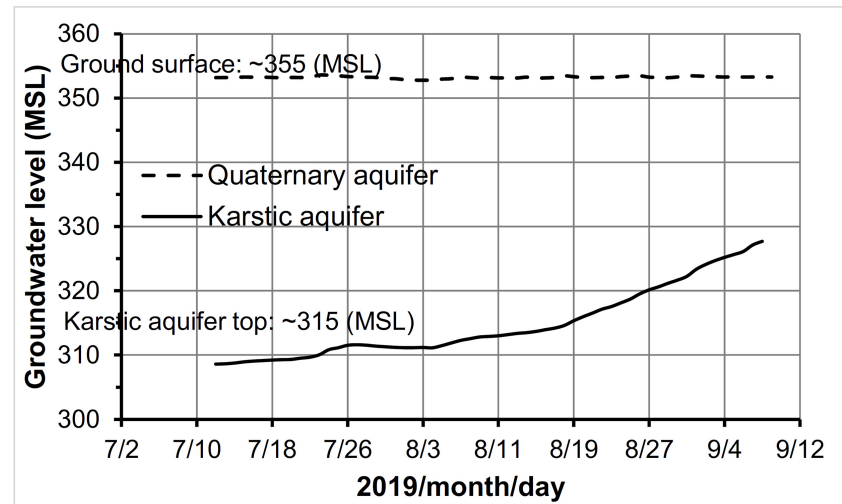

Figure 15. Observed GW level in the aquifers 1 and 3 .

formation. The soil suffusion in the lower part of aquifer 2 serves as the necessary condition for the arching failure of the above soil column to occur. During the rainy seasons, the water level increases from time to time and goes higher than the aquifer top (called high low water level in Figure 6), which would cease the soil suffusion.

Recent GW level monitoring data show that the GW level depth of the first from ground surface aquifer 1 is around $1.4-2.4 \mathrm{~m} \mathrm{(349.6}$ to 347.4 MSL). However, for the karstic aquifer 3, the water level rose dramatically from a depth of $46.41 \mathrm{~m}$ (308.59 MSL) on the 12th of July 2019 to $27.3 \mathrm{~m}$ (327.7 MSL) on the 8th of September 2019, that is, during the rainy season (Figure 15).

Therefore, aquifer 2 gets nearly saturated during the rainy seasons and completely saturated by the end of the rainy season. During the dry season, the water level of the karstic aquifer fast declines due to the dewatering of the Na Tum mine since the porosity of the aquifer is quite small, that is, the storativity and specific yield is small. The fast decline of the GW level in the aquifer leads to vertical GW flow in aquifer 2 with a high gradient. When the water level in karstic aquifer becomes lower than the bottom of aquifer 2, the gradient of the vertical flow in aquifer 2 becomes at least equal to 1 , which is a high gradient compared to the suffusion critical gradient by Istomina's criterion. An intensive suffusion occurs in aquifer 2, with the discharge of soil particles into fractures and cavities of the karstic formation. As a consequence, soil arching condition results for the above-lying soil column, and a sliding failure becomes highly possible.
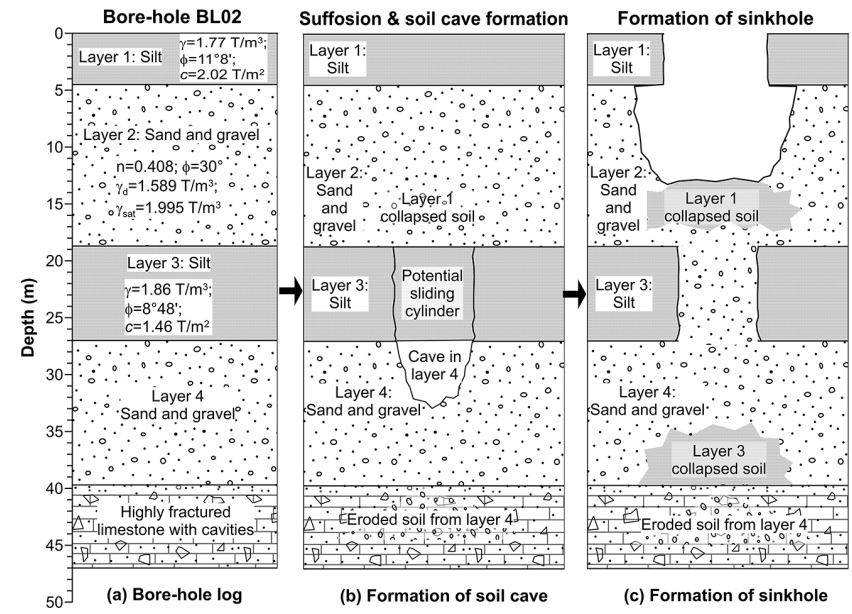

Figure 16. Geotechnical bore-hole log and formation of sinkhole.

\subsection{Sinkhole Formation as a Consequence of Soil Arching Failure}

The water level in aquifer 3 (the karstic formation) decreases steeply and falls below the sand and gravel layer 4 (aquifer 2). The soil of layer 4 is internally unstable by grain size distribution as identified above. Owing to gravity and GW seepage force, the soil layer 4 breaks and enters the karstic cavities and fractures. This leads to the formation of a cave in soil layer 4 (Figure 16b). The cave-in soil layer 4 expands wider and higher until the shear stress becomes greater than the cohesive strength of the semi-pervious soil layer 3 , which leads to the collapse of soil layer 3 (Figure 16b). Afterward, the soil sinkhole continues to expand to reach soil layer 2 (aquifer 1) until the collapse of the semipervious soil layer 1 , leading to the formation of a sinkhole on the ground surface (Figure 16 $)$.

Some physical and mechanical parameters of the soils, as shown in the bore-hole log (Figure 16a), in the middle of the plain where most sinkholes and large sinkholes have developed. The vertical suffusion of particles of soil layer 4 into the fractured limestone cavities from time to time formed an underground cave in soil layer 4 (Figure 16 b). The cave continued to expand further until failure occurs in soil layer 3 . As a consequence, layer 1 collapsed to form a sinkhole on the ground surface Figure 16.).

As the underground caves form in soil layer 3 above the karstic formation, the soil arching failures occur. The diameters of the sliding cylin- 


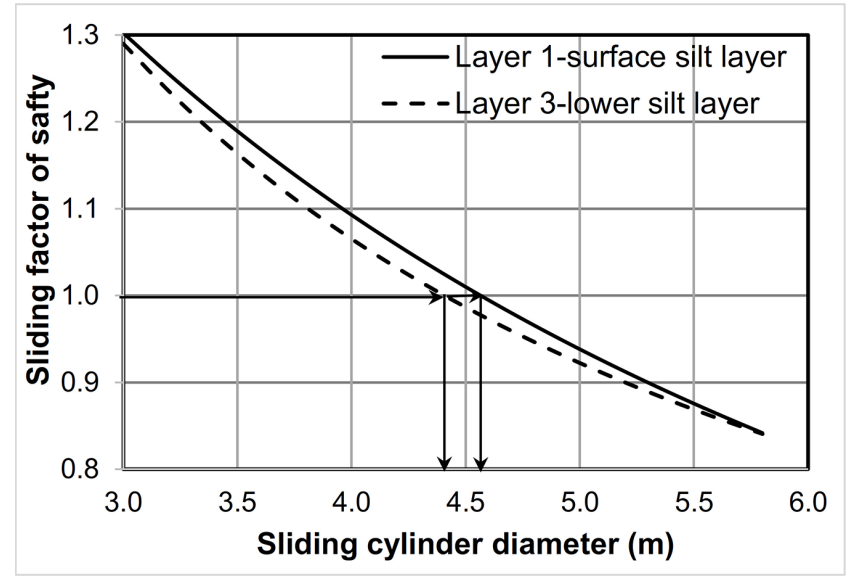

Figure 17. Safety factor of sliding: failure diameter of $4.56 \mathrm{~m}$ (layer 1), $4.41 \mathrm{~m}$ (layer 3).

der depend on the thickness of the physical and strength parameters of soil layer 3. Figure 17] shows the safety factor of sliding with cylinder diameter $D$ in soil layer 3 , in which the diameter of $4.41 \mathrm{~m}$ corresponds to the safety factor of sliding of 1 . Once the failure of soil layer 3 occurred, it led to the mass downward movement of particles of layer 2, and the diameter of the underground sinkhole in soil layer 3 expanded due to soil erosion due to the tensile cracks. Once the sinkhole in soil layer 3 reached a diameter of $4.56 \mathrm{~m}$, which is equal to the diameter of the cylinder of the arching failure in soil layer 1 (Figure 17), a sinkhole appeared on the ground surface (Figure 16;). The process of the sinkhole formation is illustrated in Figure 16.

\section{Discussion}

Most of the described suffusion criteria have been developed and proposed to study the ability of soil particles to move within the soil body under water flow. The bottom line is that different particle gradation of non-cohesive soils create different pore sizes, due to which finer particles can move in with accelerating water flow. The utilization of the criteria in analyzing the non-cohesive soil profile in the study area shows that the soil is internally unstable in terms of subsurface erosion. Some of the criteria provide a general meaning of soil suffusion, that is, whether the soil can undergo suffusion or not (Istimina's, Burenkova's, Kezdi's, Liu's, and Mao's criteria). Some of the criteria give more concrete meaning of suffusion, that is, the maximal particle diameter due to which the particles can move (Busch and Luckner's, Patrasev's, and Ziems's criteria). Several criteria have included soil porosity (Mao's, Busch and Luckner's, Patrasev's, and Ziems's criteria). Although in developing suffusion criteria, many researchers used certain hydraulic gradients in the experiments (e.g. Istomina presented her experiment gradient from about 0.24 to 1.0, Kenney and Lau carried out their experiments under gradient from 1.16 to 2.22 ), only Istomina presented the relationship between gradation and critical gradient.

Among the applied criteria, Mao's criterion has given more positive results regarding the suffusion vulnerability of the study's non-cohesive soil: $50 \%$ and $18 \%$ of the soil samples are classified as suffusion unstable with reference maximal and average porosity, respectively. This method is accepted as a formal method in levee design and sluice design according to the technical standards of China [ $\mathrm{Li}$, 2008, for which more desirable selective particle gradation materials can be selected.

Nevertheless, almost all the criteria, except Istomina's criterion, are designated for the classification of non-cohesive soils as internally stable or unstable. As per the study site's soil profile, a favorable condition for the erosion of soil grains at the exit of a seepage path (backward erosion) to underlying fractured and karstic formation does exist; non-cohesive soil overlying the karstic formation can completely undergo suffusion under gravity in unsaturated conditions or under very low vertical hydraulic gradient in saturated conditions. This consequently creates new particle size gradation which is internally unstable, that is, fine soil grains can get eroded through the voids between the coarse grains due to seepage flow, usually over the years.

The above-mentioned soil mechanic model has determined the sinkhole diameter to be $4.56 \mathrm{~m}$. However, the diameters of the sinkholes formed in the area range between $4 \mathrm{~m}$ and $20 \mathrm{~m}$. It is well known that mechanical parameters of the same soil unit in the same area vary from location to location due to soil natural inhomogeneity. Also, the mechanical parameters of the same soil change with a change in related physical parameters, out of which the most influencing parameter is the moisture content. Besides, the drying of the soil may even lead to "self-failure" as tension cracking, which results 
in zero cohesion. In addition, the thickness of the soil layers may also spatially change, although not very much. Therefore, sinkholes of different sizes would most likely be formed.

The time of sinkhole appearance is mostly during the middle of the dry season. This corresponds well with the GW level fluctuation in the karstic formation and non-cohesive sand and gravel layer above that creates suffusion. Regarding soil's mechanical properties in relation to the direct formation of a sinkhole, the surface soil can just go through a dry-wet-dry cycle, which may decrease the soil strength, that is, internal friction angle and cohesion.

From the geological point of view, the largest sinkholes in this study area were formed in the middle of the sinkhole area under consideration. This is exactly the location through which a large NW fault passes, where the most favorable conditions for sinkhole development are found as per Newton 1986; according to him, subsurface erosion caused by GW flow through unobstructed faults, joints, fractures or other openings filled with unconsolidated sediments in creating and enlarging cavities can directly create sinkholes in the eastern United States. Also, Prasad et al. 2017 had carried out an analysis which showed that faults in the southwestern part of the Cuddapah basin, India, are favorable conditions for sinkhole formations due to the secondary permeability features (faults), as all the sinkholes had formed along a fault zone, which serves as a boundary between two different formations.

\section{Concluding Remarks}

The most important site-specific factors and mechanism of sinkhole development in the study area may be summarized as follows.

- Underneath the ground surface are present two layers of sand and gravel, which are highly vulnerable to subsurface erosion by almost all different suffusion criteria.

- The underlying karstic bedrock formation has local fractures, cavities, and even large caves, which serve as a large compartment for accepting soil material flow from the sand and gravel layer above.
- Due to the dewatering of the Na Tum mine, from the middle of the rainy season to the beginning of the dry season, the water level rises to saturate the sand and gravel layer above. During the dry season, the water level of the bedrock karstic formation falls much lower than its top and creates vertical water flow in the sand and gravel layer, which leads to subsurface erosion.

- The creation of a larger hidden sinkhole within the non-cohesive sand and gravel layer 3 leads to the situation that the weight of a cylinder of a certain diameter of soil in the cohesive silt layer 3 located above becomes greater than the full frictional resistance along the vertical cylinder surface, which results in sliding of the soil cylinder. Consequently, a certain diameter cylinder of cohesion soil in surface layer 1 undergoes sliding to form a sinkhole.

Sinkholes in the study area are extremely hazardous, causing long-term social anxiety and economic damage to local residents, properties, and the Na Tum mine company. The history of sinkhole development in the study area and the quantitative analysis in this work do emphasize a high risk of sinkhole development in the future since the mine is dewatered and no land and surface water management and preventive measures have been taken since the beginning of the sinkhole formation.

Comprehensive engineering and measures to prevent future sinkhole development need to be carried out for sustainable socio-economic development and environmental protection in terms of induced geohazards related to mining activities. From this case study, an important lesson could be drawn that a comprehensive geological, hydrogeological, and geotechnical investigation is required to be carried out over a large relevant area surrounding any mine which is subject to dewatering to forecast and predict the risk of sinkhole incidence, especially in areas with carbonate and highly fractured formations.

Acknowledgments. This paper has been completed within the implementation of research project KC.08.23/ 16-20 financed by Ministry of Science and Technology of Vietnam and research project VT-UD.05/18-20 funded by Vietnam Academy of Science and Technology. 


\section{References}

Burenkova, V. V. (1993), Assessment of suffusion in noncohesive and graded soils, 1st International Conference on Filters in Geotechnical and Hydraulic Engineering p. 357-360, Balkema, Rotterdam.

Busch, K. F., L. Luckner (1972), Geohydraulics, VEB German Publishing House for Basic Material Industry, Leipzig. (in German)

Buttrick, D. B., A. Van Schalkwyk (1995), The method of scenario supposition for stability evaluation of sites on dolomitic land in South Africa, Journal of South African Institution of Civil Engineers, 37, No. 4, 4-14.

Department of Geology and Minerals of Vietnam (2005), Map of Geology and Mineral Resources of Vietnam, scale 200,000, Vietnam Ministry of Natural Resources and Environment (MONRE), Hanoi, Vietnam.

Fetter, C. W. (2001), Applied Hydrogeology. 4th Edition, 598 pp. Prentice Hall, Upper Saddle River.

Foose, R. M. (1953), Ground-water behavior in the Hershey Valley, Pennsylvania, Geological Society America Bulletin, 64, 623-645, Crossref

Hudak, M. (2009), The Phenomenon of Soil Suffusionability in the area of the Central Water Intake in Zawada near Zielona Gora, Civil and Environmental Engineering Reports. UNSW, 3, 37-43.

Istomina, V. S. (1957), Filtration Stability of Soils, Gostroizdat Publishing House, Moscow, Russia. (in Russian)

Jennings, J. E., A. B. A. Brink, et al. (1965) Sinkholes and subsidence in the Transvaal dolomites of South Africa, International Conference Soil Mechanics, 6th, 1965 proceedings p. 51-54, Foundation Engineering, Montreal.

Kenney, T. C., D. Lau (1985), Internal stability of granular filters, Can. Geotech. J., 22, No. 2, 215-225, Crossref

Kenney, T. C., D. Lau (1986), Internal stability of granular filters: Reply, Can. Geotech. J., 23, No. 4, 420-423, Crossref

Kezdi, A. (1975), Lateral Earth Pressure, Foundation Engineering Handbook. Winterkorn H. F. \& Fang, H. Y. (Eds.) p. 197-220, Van Nostrand Reinhold Company, New York.

Li, M. (2008), Lateral Earth Pressure, Seepage Induced Instability in Widely Graded Soils A PhD thesis, The University of British Columbia, British Columbia.

Liu, J. (2005), Seepage Control of Earth-Rock Dams: Theoretical Basis, Engineering Experiences and Lessons, 219 pp. China Waterpower Press, Beijing. (in Chinese)

Lomtadze, V. D. (1977), Engineering Geology: Engineering Geodynamics, Nedra, Leningrad. (in Russian)

Lowe, D., T. Waltham (2002), Dictionary of karst and caves, British Cave Research Association Cave Studies, 10, 1-40.
Mao, C. X. (2005), Study on piping and filters: Part I of piping, Rock and Soil Mechanics, 26, No. 2, 209-215. (in Chinese)

Morris, D. A., A. I. Johnson (1967), Summary of Hydrologic and Physical Properties of Rock and Soil Materials, as Analyzed by the Hydrologic Laboratory of the U.S. Geological Survey, 1948-1960 USGS Water Supply Paper: 1839-D, Geological Survey, U.S. Crossref

Newton, J. G. (1986), Natural and Induced Sinkhole Development in the Eastern United States, International Association of Hydrogeological Sciences, Publication 151. (http:// hydrologie.org/redbooks/ a151/iahs_151_0549.pdf)

Patrasev, A. N. (1957), Method of Selection of Graduation Materials for Reverse Filters. Technical Report, Lengiprorectrans, Leningrad. (in Russian)

Prasad, M., Reddy M. Ramakrishna, V. Sunitha (2017), Bedrock Structural Controls on the Occurrence of Sinkholes: A Case Study from Chintakommadinne Area, Part of Cuddapah Basin, South India, J. Ind. Geophys. Union, 21, No. 2, 124-139.

Riha, J., Z. Alhasan, et al. (2019), Harmonisation of terminology and definitions on soil deformation due to seepage, Internal Erosion in Earthdams, Dikes and Levees. EWG-IE 2018. Lecture Notes in Civil Engineering, vol 17, Bonelli S., Jommi C., Sterpi D. (eds.) Springer, Cham.. Crossref

Semar, O., K. Witt, R. Fannin (2010), Suffusion Evaluation - Comparison of Current Approaches, Proceedings of International Conference on Scour and Erosion ASCE p. 251-260, Crossref

Sinclair, W. C. (1982), Sinkhole development resulting from ground-water withdrawal in the Tampa area, Florida, Water-Resources Investigations p. 5081, Geological Survey, U.S.

Spigner, B. C. (1978), Land Surface Collapse and Ground-Water Problems in the Jamestown Area, South Carolina. Water Resources Commission OpenFile Report no. 78-1, 99 pp. Water Resources Commission, South Carolina.

Terzaghi, K. (1943), Theoretical Soil Mechanics, 510 pp. John Wiley \& Sons, Crossref

Thiem, G. (1906), Hydrologische Methoden, J. M. Gebhardt, Leipzig.

Tran, Trung Kien, Quang Tu Pham (2011), The role of NGOs in policy criticism: The case of the Consultancy on Development Institute in the sustainable management of mineral resources in Vietnam. The Consultancy on Development Institute, CODE, Vietnam. (in Vietnamese)

Tran, Tuan Anh, I. V. Gaskov, et al. (2011), Mineralogical and geochemical characteristics and forming conditions of lead - zinc deposits in Lo Gam structure, Northern Vietnam, Vietnam Journal of Earth Sciences, 33, No. 3/211, 393-408.

Urumović, K., K. Sr. Urumović (2016), The referential grain size and effective porosity in the KozenyCarman model, Hydrol. Earth Syst. Sci., 20, 1669 1680, Crossref 
Vietnam Consultancy Joint Stock Company (2017), Environmental Impact Assessment Report: Investment project of construction of lead and zinc mineral processing zone to recover accompanying tin, silver minerals and iron and manganese ore, Bac Kan Mining Company Ltd, Vietnam. (in Vietnamese)

Waltham, A. C. (2008), Sinkhole hazard case histories in karst terrains, Quarterly Journal of Engineering Geology and Hydrogeology, 41, 291-300, Crossref

Waltham, A. C., P. G. Fookes (2003), Engineering classification of karst ground conditions, Quar- terly Journal of Engineering Geology and Hydrogeology, 36, 101-118, Crossref

Ziems, J. (1969), Engineering classification of karst ground conditions, Contribution to contact erosion of cohesionless earth materials. PhD thesis, Techn. Univ., Dresden, Germany. (in German)

\section{Corresponding author:}

Nguyen Van Hoang, Institute of Geological Sciences (IGS) - VAST, Hanoi,Vietnam. (n_v_hoang_vdc@yahoo. com) 